\title{
Risk-Return Dynamics of Cross-listed Stocks
}

\author{
Ming Jing Yang ${ }^{1}$ \\ ${ }^{1}$ Department and Graduate Institute of Finance, College of Finance, Feng Chia University, Taichung, Taiwan \\ Correspondence: Ming Jing Yang, Department and Graduate Institute of Finance, College of Finance, Feng Chia \\ University, Taichung 40724, Taiwan.
}

Received: September 16, 2017

Accepted: October 23, 2017

Online Published: October 25, 2017

doi:10.5430/afr.v6n4p294

URL: https://doi.org/10.5430/afr.v6n4p294

\begin{abstract}
Since US has been playing a leading role in global economy and technology, any major price changes in the American stock market may affect other stock markets worldwide. The American Depositary Receipts (ADRs), being the substitutes for the foreign securities, provide American investors with appealing investment opportunities to form international portfolios and to achieve the international diversification benefits. These stocks cross-listed on different exchanges not only assist corporations in raising capital abroad, but also provide a better channel for firms to search for price efficiency across the international capital markets. Consequently, the objective of this study is to examine the risk and return dynamics between ADRs and their underlying securities. The empirical results of this study indicate that the mean and volatility spillover effects and information transmission between ADRs and their underlying securities are bi-directional for the Taiwanese securities, but uni-directional (from the underlying securities to their ADRs) for the Chinese securities. Furthermore, while the international center hypothesis and the home bias hypothesis are both supported for the Taiwanese securities cross-listed in US stock markets, this study also provides evidence more in favor of the home bias hypothesis for the Chinese ADRs and their underlying securities.
\end{abstract}

Keywords: International Portfolios, Cross-listed Stocks, Risk-Return Dynamics

\section{Introduction}

The fast growth in international trade and globalization of economy have accelerated the mobility of international capital and the interaction of international financial markets. In addition, the liberalization and internationalization of the financial markets have also resulted in an increasing tendency of raising capital in global equity markets through cross-listing on foreign security exchanges, for instance in the form of depositary receipts (DRs). All these have provided investors with excellent investment opportunities to form their international portfolios.

American Depositary Receipts (ADRs) were designed by J. P. Morgan on April 29, 1927 to allow American investors to invest in the stocks of Selfridges Provincial Stores Limited in UK. At that time, US government restrictions prevented American investors from investing directly in UK stock markets. In response to American investors' request, a special US financial instrument had to be created to overcome the restrictions on foreign investment. The Securities and Exchange Commission (SEC) announced the legal substitution of ADRs in 1955, and it has been a trend to take advantage of ADRs to invest in foreign securities ever since. ADRs are negotiable certificates, traded on the US stock exchanges in US dollars, representing ownership of the foreign underlying securities, and thus offering US investors additional investment opportunities. The major advantages of issuing ADRs are increasing the liquidity of the securities, reducing the costs of capital, promoting the reputation of the companies, broadening the firms' global shareholder base, enhancing the visibility of the companies in the American market, stabilizing their stock prices, and avoiding the foreign investment barriers for US investors. Therefore, ADRs provide US investors with a great opportunity to diversify their portfolios globally without being exposed to foreign exchange risk.

After the Asian financial crisis, US capital market has become a relatively attractive market for multinational corporations to raise capital abroad and its trading volume has steadily increased. Since US market is generally considered to have the leading position in global economy and information technology, any major price changes in the American stock market may affect other stock markets worldwide. The American Depositary Receipts, being the substitutes for the foreign securities, provide American investors with appealing investment opportunities to form international portfolios and to achieve the international diversification benefits. These stocks cross-listed on foreign stock exchanges represent the underlying securities in their domestic markets. Hence, under the assumptions of perfectly integrated markets, the exchange-rate-adjusted expected returns of the stocks in the domestic markets and 
the foreign markets would be equivalent. By studying the connection between the prices of the cross-listed stocks, the transmission efficiency of the prices in the international capital markets can be observed. Therefore, these stocks cross-listed on different exchanges not only assist corporations in raising capital abroad, but also provide a better channel for firms to search for price efficiency across the international capital markets.

Moreover, the transmission of volatility, resulting from the price changes, can also be affected by the patterns of information flows. Investigating the volatility spillover effect between different markets is useful for us to understand the process of information transmission between these markets, and the movement and the source of volatility. In addition, it also helps investors design the appropriate international hedging strategies and asset allocation decisions.

Furthermore, two hypotheses related to the patterns of information transmission across the international capital markets are also examined, i.e. the home bias hypothesis and the international center hypothesis. The home bias hypothesis indicates that information flows between markets mainly arise from the home market. In other words, the home market plays a dominant role in transmitting information across different markets. The international center hypothesis implies that a financial center, the US market for instance, plays a leading role in delivering information to other financial markets. Consequently, the objective of this study is to examine the information transmission dynamics of returns and volatilities between ADRs and their underlying securities.

The remainder of this paper is arranged as follows. Section 2 reviews the related literature. Section 3 describes the data and methodology of the research. Section 4 analyzes the empirical results. Finally, the conclusions of this paper are summarized in section 5 .

\section{Literature Review}

The review of previous literature on information transmission dynamics focuses on two major categories, including the information transmission among international capital markets, and the relationships between ADRs and their underlying stocks.

\subsection{Information Transmission among International Capital Markets}

Various studies have examined the correlation and transmission effect of the price changes across different markets. Eun and Shim (1989), and Jeong (1999) explore the international transmission process of stock market movements by using the vector autoregressive (VAR) models and multivariate generalized autoregressive conditional heteroscedasticity $(\mathrm{GARCH})$ models, respectively. These studies generally support the notion of informational efficiency in international stock markets. Moreover, Koulakiotis et al. (2006) also find evidence of the volatility transmission across different markets by using the GARCH models. Lee and Rui (2002) discover that there is a positive feedback relationship between the return volatility and trading volume in London, Tokyo, and New York stock markets by employing the VAR models. Sheng et al. (2017) also point out that trading volume delivers essential information that is useful to explain the international stock return comovements. However, Niarchos et al. (1999) investigate the information interaction between Greek and US stock markets using the bivariate exponential GARCH-t model, and they find that two markets are not related to each other either in the long run or in the short run. Nevertheless, Kim (2003) points out that there is a complex series of significant market responses in Asia-Pacific stock markets to the US and Japanese public economic announcements by using a parsimonious EGARCH model.

If international capital markets are integrated and efficient, the volatility of returns could be caused by the new information generated not only from one specific market but also from another market, indicating the volatility spillover effects. Previous studies have investigated the return and volatility spillover effects across different markets. Lee et al. (2004) apply the EGARCH model and document the significant return and volatility spillovers from NASDAQ to Asian markets. Hamao et al. (1990) study the interaction of volatilities among the New York, London, and Tokyo stock markets, and they find the volatility spillovers from the US and UK markets to the Japanese stock market. Theodossiou and Lee (1993) examine the information transmission across US, Germany, Japan, UK, and Canada by employing the GARCH-M models, and they point out that there are positive mean return spillovers from US to Canada, Germany, and UK stock markets, and that the cross-volatility spillovers are significantly persistent from US to other stock markets. Wei et al. (1995) apply GARCH-M model and document that the New York stock market has greater impact than the Tokyo stock market does on the Taiwanese and Hong Kong stock markets. Moreover, $\mathrm{Ng}$ (2000) also provides evidence of the mean return and volatility spillover effects from the US and Japan to Asian emerging stock markets. A general finding in the previous studies is the status of the US market in leading other major markets and the volatility of stock returns is time-varying across different markets.

Besides the US market, the information spillover effects have also been discovered in other stock markets. Booth et al. (1997) explore the volatility and price spillovers among the Scandinavian stock markets using the multivariate 
EGARCH models. Their findings imply that there is a major price spillover effect from Norway to Denmark and Sweden and from Sweden to Finland and the volatility spillover between Sweden and Finland is significant, and the Scandinavian stock markets are more responsive to bad news than to good news except Denmark. Wang et al. (2002) employ the GJR-GARCH model to examine the returns and volatilities of stocks traded in the non-synchronous international markets, including stock exchanges of Hong Kong and London. They find that the one-period lagged return and volatility spillovers are from Hong Kong to London, though the contemporaneous returns and volatility spillovers are bidirectional. Huo and Ahmed (2017) demonstrate that there is a long-term cointegration relationship between the Shanghai and Hong Kong stock markets, and the return and volatility spillover effects from Shanghai to Hong Kong are faster and stronger after the introduction of Shanghai-Hong Kong Stock Connect Program. Huang et al. (2016) also point out that Chinese stocks which are cross-listed in the Hong Kong stock market have lower transaction costs and better liquidity than those not cross-listed. However, Kot and Tam (2016) examine Chinese firms first listed in the Hong Kong market (H-share firms) and then dual-listed in the Chinese market, and they suggest that market integration may bring about more trading, but it may not necessarily result in a more efficient capital market.

\subsection{The Determinants of the ADR Returns}

ADRs offer a great opportunity to explore the information transmission process since they are traded in the US domestic markets but stand for ownership of the underlying foreign securities. Assuming that there are no investment barriers and the international markets are efficient capital markets, the ADRs and their foreign underlying securities will be priced equivalently. Moreover, if the prices of foreign underlying securities correspondingly affect the prices of their ADRs, the shocks from the foreign underlying securities should be reflected in the prices of their ADRs accordingly. Prior studies on ADRs have focused on whether there are some arbitrage opportunities existing between the prices of ADRs and their foreign underlying securities. Jiang (1998) suggests that the US market returns, the orthogonal local market returns and currency returns are important pricing factors in explaining ADRs returns. Kim et al. (2000) use the prices of the underlying securities, exchange rates, and S\&P500 index as the risk factors to explain the prices of ADRs. They suggest that ADR prices appear to under-react to the price changes of the underlying securities and exchange rates, but over-react to the changes in S\&P500 index. Patro (2000) explores the return behavior and the pricing of ADRs using the SUR method and documents that the returns of ADRs are affected by the returns of their individual local market portfolios and the world market portfolio. Choi and Kim (2000) find that the prices of the underlying securities, the industry indices, and the world index are important determinants of the ADR prices. They conclude that the ADRs with their underlying securities from emerging markets provide US investors with substantial international diversification benefits. Kutan and Zhou (2006) analyze the determinants of returns and volatility for the Chinese ADRs. They find that the returns of the underlying securities, local market, and host market are all key determinants of the ADR returns, but only the innovations in the underlying securities have a significant impact on the volatility of the ADRs. Generally, the findings from the previous studies suggest that the change in prices of the foreign underlying securities is a main pricing factor in describing ADR returns.

\subsection{The Impact of International Listings}

The international listings involve direct listings of stocks in foreign markets and also via ADRs. ADRs are negotiable certificates traded on US stock exchanges in US dollars, representing ownership of the foreign underlying securities, with prices relating to their underlying securities. Many studies have investigated the impacts of international listings on the risk and returns of the foreign underlying securities. Martell et al. (1999) investigate the influence of Latin American ADR introduction on the risk and returns of the underlying stocks. Their results reveal no systematic effects on the risk of the underlying Latin American stocks subsequent to the introduction of their ADRs. Ejara and Ghosh (2004) examine the trading liquidity and volatility of the domestic stock market following ADR listings in U.S stock markets. Their empirical results are stated as follows. First, the volatility and trading volume of the domestic stock market significantly increase after ADR listings. Second, the liquidity improves and trading friction decreases in the domestic stock market after ADR listings. Third, trading volume significantly increases for auction type markets more than for dealer type markets, but the volatility significantly increases for dealer type markets more than for auction type markets. Ghadhab and Hellara (2016) find that compared with cross-listing on the European stock exchanges, cross-listing on the US stock exchanges provides more important contributions to the price discovery for stocks listed abroad. Besides, Dodd and Gilbert (2016) also document that there is a significant improvement in the quality of the firms' information environment and stock price efficiency in the local market after cross-listing in the U.S. markets. 


\subsection{The Relationship between ADRs and Their Underlying Stocks}

More recently, many studies explore the price transmission dynamics between ADRs and their underlying foreign securities. For example, Jiang (1998) explores the dynamic relations between ADRs and local market portfolios, and confirms that interrelationships exist in international capital markets in most cases. He points out that ADRs are influenced by their corresponding local market portfolios in general, whereas the influence of ADRs on local market portfolios is also significant when ADR and local market portfolios are cointegrated. Moreover, Jiang (1998) finds that the US market returns, the orthogonal local market returns, and currency returns are important in explaining the variations of ADR returns. Fatemi and Park (1996) and Park (1995) investigate the dynamic relations between Japanese ADRs and the underlying securities, and they also find that Japanese ADR returns are generally affected by the US stock market. Nevertheless, Alaganar and Bhar (2001) analyze the Australian ADRs listed in the US market, and they find that the Australian ADR returns are less correlated with the US stock market returns, providing the diversification benefits to the US investors. They also document the unidirectional information flow from the underlying Australian stocks to the ADRs. Alaganar and Bhar (2002) use the bivariate GARCH model to investigate the information flow between portfolios of ADRs and the underlying stocks. They demonstrate that the information flow from the underlying foreign stocks to the ADRs tends to lessen the information flow from the US market to the foreign local markets. Howe and Ragan (2002) investigate the flow of information and price discovery process for the non-US securities with their underlying shares traded in their local markets and ADRs traded on the NYSE. Their results prove that the price discovery of the ADRs on NYSE is improved when the tradings of the ADRs and their underlying securities are overlapping, and the NYSE becomes the prevailing market when the ADRs and their underlying securities are both traded simultaneously.

\section{Research Design}

\subsection{Data Description}

In order to examine the risk-return dynamics for ADRs and their underlying securities, the data used in the empirical analysis include the daily exchange rates, the shares outstanding, and the opening and closing prices of the ADRs and their underlying foreign securities for Chinese firms and Taiwanese firms with ADRs traded on the NYSE, AMEX, or NASDAQ. The Chinese and Taiwanese sample data are collected from the DataStream International, CRSP, Compustat Global, and Taiwan Economic Journal (TEJ) Databases for the period from January 4, 2002 to December 30, 2016.

\subsection{Data Processing}

Let $S O P_{i, t}$ and $S C P_{i, t}$ be the opening price and closing price of the underlying security $i$ at time $t$, respectively. $R X_{t}$ denotes the percentage change in exchange rates at time $t . R S N u_{i, t}$ and $R S D u_{i, t}$ represent the unadjusted overnight return and the unadjusted daytime return of the underlying security $i$ at time $t$, respectively, measured in the local currency. The daily returns of the underlying security $i$ at time $t, R S_{i, t}$, is then divided into the exchange rate adjusted overnight return, $R S N_{i, t}$, and the exchange rate adjusted daytime return, $R S D_{i, t}$, measured in US dollar, based on the method proposed by Hamao et al. (1990).

$$
\begin{gathered}
R S_{i, t}=R S N_{i, t}+R S D_{, t}, \\
\text { where } R S N_{i, t}=\left(1+R S N u_{i, t}\right)\left(1+R X_{t}\right)-1.0, R S D_{, t}=\left(1+R S D u_{i, t}\right)\left(1+R X_{t}\right)-1.0, \\
R S N u_{i, t}=\ln \left(S O P_{i, t} / S C P_{i, t-1}\right) \text {, and } R S D u_{i, t}=\ln \left(S C P_{i, t} / S O P_{i, t}\right) .
\end{gathered}
$$

Similarly, let $A O P_{i, t}$ and $A C P_{i, t}$ be the opening price and closing price of the ADR $i$ at time $t$, respectively. The daily returns of the ADR $i$ at time $t, R A_{i, t}$, is also divided into the overnight return, $R A N_{i, t}$, and the daytime return, $R A D_{i, t}$, measured in US dollar:

$$
R A_{i, t}=R A N_{i, t}+R A D_{i, t},
$$

where $R A N_{i, t}=\ln \left(A O P_{i, t} / A C P_{i, t-1}\right)$, and $R A D_{i, t}=\ln \left(A C P_{i, t} / A O P_{i, t}\right)$.

Moreover, the information from individual firms is further exploited to form portfolios for the ADRs and their underlying foreign securities, respectively. The overnight return and the daytime return of the underlying stock portfolio $p$ at time $t, R S N_{p, t}$ and $R S D_{p, t}$, are computed as the value-weighted average of the returns of individual underlying securities in the portfolio. Likewise, the overnight return and the daytime return of the ADR portfolio $p$ at time $t, R A N_{p, t}$ and $R A D_{p, t}$, are also computed as the value-weighted average of the returns of individual ADRs in the portfolio. 


\subsection{Econometric Tests on the Time Series Properties}

The main purpose of the unit root tests is to identify the order of integration in economic time series, and determine whether the time series are stationary. If the time series do not have unit roots, they are stationary. However, many economic time series contain unit roots (Nelson and Plosser, 1982). Granger and Newbold (1974) propose that non-stationary variables employed in a regression analysis can cause spurious regression results. Therefore, it is important to examine the stationarity of a time series before the regression analysis by the unit root tests. The Augmented Dickey-Fuller (ADF) (Said and Dickey, 1984), the Phillips-Perron (PP) (Phillips and Perron, 1988), and the Kwiatkowski-Phillips-Schmidt-Shin (KPSS) (Kwiatkowski et al., 1992) unit root tests are employed in this study.

In time series analysis, the non-stationary data are often transformed to become stationary by differencing; however, it may result in the loss of long-term information among variables. Engle and Granger (1987) suggest using the cointegration test to explore the long-term equilibrium relationship when the time series are nonstationary. This study will employ the Engle and Granger two-step cointegration test (Engle and Granger, 1987) and Johansen cointegration test (Johansen, 1988) to examine whether a cointegration relationship exists between the prices of the ADRs and their underlying foreign securities. The Ljung-Box test is also applied to examine whether the autocorrelation exists in the time series of the standardized residuals and squared standardized residuals. Furthermore, this study will use the Lagrange Multiplier (LM) test suggested by Engle (1982) to assess the significance of the autoregressive conditional heteroscedastic (ARCH) effects in the time series of the squared residuals. In addition, the volatility specification tests proposed by Engle and Ng (1993), including the sign bias test (SBT), the negative size bias test (NSBT), the positive size bias test (PSBT), and the joint test (JT), will also be applied to examine the asymmetric reactions associated with the time series of the squared standardized residuals.

\subsection{Empirical Model Specifications}

The ARCH models presented by Engle (1982) describe some of the empirical patterns of equity returns. In the ARCH models, the conditional variance is affected by the lagged squared residuals, implying that the conditional variance changes over time instead of being constant. Bollerslev (1986) extends the ARCH models as the GARCH models, where the conditional variance acts as a function of the lagged squared residuals and the lagged conditional variances. The GARCH models assume that mean and volatility of stock returns react symmetrically to negative and positive shocks. However, some empirical evidence suggests that the conditional variance exhibits different responses to the negative and positive shocks. Several different GARCH model specifications have been recommended to describe the asymmetric characteristics of volatility responses. Kim and Kon (1994) find that the GJR-GARCH models are more descriptive of the time-varying volatility for individual stock returns. Therefore, this study employs the two-stage bivariate GJR-GARCH models to analyze the information transmission dynamics of returns and volatilities for the Chinese and Taiwanese ADRs and their underlying foreign securities.

In the first stage, the overnight returns of the ADRs and their underlying stock portfolios are used to extract the information (the unexpected shocks). The empirical models in the first stage are described as follows:

$$
\begin{aligned}
& R A N_{t}=\phi_{A N, 0}+\sum_{i=1}^{A 1} \phi_{A N^{+}, i} R A N_{t-i}^{+}+\sum_{i=1}^{A 1} \phi_{A N^{-}, i} R A N_{t-i}^{-} \\
& +\sum_{j=1}^{S 1} \phi_{S N^{+}, j} R S N_{t-j}^{+}+\sum_{j=1}^{S 1} \phi_{S N^{-}, j} R S N_{t-j}^{-}+\gamma_{A N} e c a_{t-1}+e_{A N, t} \\
& R S N_{t}=\psi_{S N, 0}+\sum_{j=1}^{S 1} \psi_{S N^{+}, j} R S N_{t-j}^{+}+\sum_{j=1}^{S 1} \psi_{S N^{-}, j} R S N_{t-j}^{-} \\
& +\sum_{i=1}^{A 1} \psi_{A N^{+}, i} R A N_{t-i}^{+}+\sum_{i=1}^{A 1} \psi_{A N^{-}, i} R A N_{t-i}^{-}+\gamma_{S N} e c s_{t-1}+e_{S N, t} \\
& h_{A N, t}=\alpha_{A N, 0}+\alpha_{A N, 1} h_{A N, t-1}+\alpha_{A N, 2}\left(e_{A N, t-1}\right)^{2}+\delta_{A N, 1} I_{t-1}\left(e_{A N, t-1}\right)^{2} \\
& +\alpha_{A N, 3}\left(e_{S N, t-1}\right)^{2}+\delta_{A N, 2} I_{t-1}\left(e_{S N, t-1}\right)^{2} \\
& h_{S N, t}=\alpha_{S N, 0}+\alpha_{S N, 1} h_{S N, t-1}+\alpha_{S N, 2}\left(e_{S N, t-1}\right)^{2}+\delta_{S N, 1} I_{t-1}\left(e_{S N, t-1}\right)^{2} \\
& +\alpha_{S N, 3}\left(e_{A N, t-1}\right)^{2}+\delta_{S N, 2} I_{t-1}\left(e_{A N, t-1}\right)^{2} \\
& h_{A N, S N, t}=\rho_{1} \sqrt{h_{A N, t} h_{S N, t}}
\end{aligned}
$$

To observe the influence of positive and negative information from the overnight returns of the ADRs and their 
underlying securities, we divide the lagged returns of the $R A N$ and $R S N$ into the positive $\left(R A N^{+}>0, R S N^{+}>0\right)$ and negative terms $\left(R A N^{\top}<0, R S N^{\top}<0\right)$, as expressed in the mean equations (3) and (4). If the coefficients $\phi_{S N^{+}, j}$ and $\phi_{S N^{-}, j}$ are statistically significant, the lagged overnight returns of the underlying securities would help explain the overnight returns $\left(R A N_{t}\right)$ of the ADRs. Furthermore, if the coefficients $\psi_{A N^{+}, i}$ and $\psi_{A N^{-, i}}$ are statistically significant, it implies that the prior overnight returns of the ADRs would forecast the overnight returns $\left(R S N_{t}\right)$ of underlying securities. The eca represents the error-correction term between the opening prices of the ADRs and the same-period closing prices of their underlying foreign securities, while the ecs is the error-correction term between the opening prices of the underlying foreign securities and the prior-period closing prices of their ADRs, after considering the differences in time zones between the ADRs (in US) and their underlying foreign securities (in Asia). The main purpose of the first-stage model is to estimate the residual terms, $e_{A N, t}$ and $e_{S N, t}$. The $e_{A N, t}$ and $e_{S N, t}$ stand for the unexpected returns (shocks) that cannot be predicted based on the information from the prior overnight returns of the ADRs and their underlying securities, respectively. Besides, in the variance equations (5) and (6), we use the variable $I_{t-1}\left(e_{t-1}\right)^{2}$ to describe the asymmetric effects of the prior negative innovations on the conditional volatility ( $h_{A N, t}$ and $h_{S N, t}$ ), where $I_{t-1}$ is an indicator variable that equals 1 if $e_{t-1}<0$, and 0 otherwise. If the coefficient $\delta$ is significantly positive, it implies that the impact from the negative shocks would be greater than that from the positive shocks.

In the second stage, we further examine the possible asymmetric reactions of the means and volatilities of the daytime returns for the ADRs and their underlying securities, by considering the exogenous influence from the additional information of the overnight returns on the ADRs and their underlying securities as well. The empirical models in the second stage are described as follows:

$$
\begin{aligned}
R A D_{t}= & \phi_{A D, 0}+\sum_{i=1}^{A 2} \phi_{A D^{+}, i} R A D_{t-i}^{+}+\sum_{i=1}^{A 2} \phi_{A D^{-}, i} R A D_{t-i}^{-}+\sum_{j=1}^{S 2} \phi_{S D^{+}, j} R S D_{t-j}^{+}+\sum_{j=1}^{S 2} \phi_{S D^{-}, j} R S D_{t-j}^{-} \\
+ & \sum_{i=0}^{m} \theta_{A N, i} e_{A N, t-i}+\sum_{j=0}^{n} \theta_{S N, j} e_{S N, t-j}+\gamma_{A D} e c a_{t-1}+\varepsilon_{A D, t} \\
R S D_{t}= & \psi_{S D, 0}+\sum_{j=1}^{S 2} \psi_{S D^{+}, j} R S D_{t-j}^{+}+\sum_{j=1}^{S 2} \psi_{S D^{-}, j} R S D_{t-j}^{-}+\sum_{i=1}^{A 2} \psi_{A D^{+}, i} R A D_{t-i}^{+}+\sum_{i=1}^{A 2} \psi_{A D^{-}, i} R A D_{t-i}^{-} \\
+ & \sum_{i=1}^{m} \lambda_{A N, i} e_{A N, t-i}+\sum_{j=0}^{n} \lambda_{S N, j} e_{S N, t-j}+\gamma_{S D} e c s_{t-1}+\varepsilon_{S D, t} \\
h_{A D, t}=\alpha_{A D, 0} & +\alpha_{A D, 1} h_{A D, t-1}+\alpha_{A D, 2}\left(\varepsilon_{A D, t-1}\right)^{2}+\delta_{A D 1} I_{t-1}\left(\varepsilon_{A D, t-1}\right)^{2}+\alpha_{A D, 3}\left(\varepsilon_{S D, t-1}\right)^{2} \\
& +\delta_{A D 2} I_{t-1}\left(\varepsilon_{S D, t-1}\right)^{2}+\sum_{i=0}^{r 2} \beta_{A N, i}\left(e_{A N, t-i}\right)^{2}+\sum_{j=0}^{r 3} \beta_{S N, j}\left(e_{S N, t-j}\right)^{2} \\
h_{S D, t}=\alpha_{S D, 0}+ & \alpha_{S D, 1} h_{S D, t-1}+\alpha_{S D, 2}\left(\varepsilon_{S D, t-1}\right)^{2}+\delta_{S D 1} I_{t-1}\left(\varepsilon_{S D, t-1}\right)^{2}+\alpha_{S D, 3}\left(\varepsilon_{A D, t-1}\right)^{2} \\
& +\delta_{S D 2} I_{t-1}\left(\varepsilon_{A D, t-1}\right)^{2}+\sum_{i=1}^{r 2} \omega_{A N, i}\left(e_{A N, t-i}\right)^{2}+\sum_{j=0}^{r 3} \omega_{S N, j}\left(e_{S N, t-j}\right)^{2} \\
h_{A D, S D, t}= & \rho_{2} \sqrt{h_{A D, t} h_{S D, t}}
\end{aligned}
$$

To observe the influence from positive and negative information of the daytime returns of the ADRs and their underlying securities, we also divide the lagged returns of the $R A D$ and $R S D$ into the positive $\left(R A D^{+}>0, R S D^{+}>0\right)$ and negative terms $\left(R A D^{-}<0, R S D^{-}<0\right)$, as expressed in the mean equations (8) and (9). The variables $e_{A N, t-i}$ and $e_{S N, t-j}$, representing the unexpected shocks from the overnight returns of the ADRs and their underlying securities, respectively, are included in the mean equations (8) and (9) as the exogenous variables to explain the daytime returns $\left(R A D_{t}\right.$ and $\left.R S D_{t}\right)$ of the ADRs and their underlying securities. The coefficients $\theta$ and $\lambda$ for the exogenous variables would measure the degree of the mean spillover effects from the unexpected overnight returns to the daytime returns. If the coefficient is significant, it represents that the mean spillover effects exist on the ADRs and their underlying securities. Similarly, the unexpected shocks $\left(\left(e_{A N, t-i}\right)^{2}\right.$ and $\left.\left(e_{S N, t-j}\right)^{2}\right)$ from the overnight returns of the ADRs and their underlying securities, respectively, are further included in the conditional variance equations (10) and (11) as the exogenous variables to explain the volatility $\left(h_{A D, t}\right.$ and $\left.h_{S D, t}\right)$ of the daytime returns on the ADRs and their underlying securities. The coefficients $\beta$ and $\omega$ for the exogenous variables would measure the degree of the volatility spillover effects from the shocks of the unexpected overnight returns to the volatility of the daytime returns on the ADRs and their underlying securities. The lagged and contemporaneous spillover effects on 
the means and volatilities of the daytime returns from the information of the overnight returns for ADRs and their underlying securities are both considered in the model, after considering the differences in time zones between the ADRs and their underlying foreign securities.

Therefore, the two-stage bivariate GJR-GARCH models discussed above not only take into account the possible interdependence between the overnight returns and the daytime returns of both the ADRs and their underlying securities, but also reflect the information transmission dynamics of returns and volatilities between the ADRs and their underlying foreign securities.

\section{Analysis of the Empirical Results}

\subsection{Results of the Econometric Tests}

Our research samples include the ADRs and their underlying foreign securities for Chinese firms and Taiwanese firms, respectively, with ADRs traded on the NYSE, AMEX, or NASDAQ. The overnight returns and daytime returns of the underlying foreign securities are adjusted for the percentage change in exchange rates and measured in US dollar.

First, the ADF, PP, and KPSS unit root tests are employed to assess the stationarity of the time series data for the opening prices and closing prices of the ADRs and their underlying foreign securities for the Chinese firms and Taiwanese firms, respectively. Table 1 indicates that the ADF and PP unit root test statistics for the opening prices and closing prices of the ADRs and their underlying securities are insignificant. However, after taking the first difference of the time series data, the test statistics are statistically significant. The similar but inverse findings are also shown in the KPSS test results. It reveals that while the original time series data are non-stationary, the changes in the opening prices and closing prices of the ADRs and their underlying securities become stationary.

Table 1. Results of the unit root tests to assess the stationarity of the time series data

\section{Panel A:}

Chinese ADR

\section{Chinese underlying securities}

\begin{tabular}{|c|c|c|c|c|c|c|c|c|}
\hline & \multicolumn{2}{|c|}{ Opening prices } & \multicolumn{2}{|c|}{ Closing prices } & \multicolumn{2}{|c|}{ Opening prices } & \multicolumn{2}{|c|}{ Closing prices } \\
\hline & $\begin{array}{l}\text { Price } \\
\text { level }\end{array}$ & $\begin{array}{c}\text { First } \\
\text { difference }\end{array}$ & $\begin{array}{l}\text { Price } \\
\text { Level }\end{array}$ & $\begin{array}{c}\text { First } \\
\text { difference }\end{array}$ & $\begin{array}{l}\text { Price } \\
\text { level }\end{array}$ & $\begin{array}{c}\text { First } \\
\text { difference }\end{array}$ & $\begin{array}{l}\text { Price } \\
\text { level }\end{array}$ & $\begin{array}{c}\text { First } \\
\text { difference }\end{array}$ \\
\hline $\mathrm{ADF}$ & -1.63756 & $-56.96898^{* * *}$ & -1.89351 & $-63.55602^{* * *}$ & -1.20982 & $-61.07479^{* * *}$ & -1.10665 & $-59.24056^{* * *}$ \\
\hline PP & -1.57909 & $-56.96764^{* * *}$ & -1.96240 & $-63.73697^{* * *}$ & -1.17901 & $-61.03112^{* * *}$ & -1.14919 & $-59.19431^{* * *}$ \\
\hline KPSS & $1.32335^{* * * *}$ & 0.28276 & $1.32558^{* * * *}$ & 0.29987 & $3.55076^{* * * *}$ & 0.17530 & $3.54388^{* * * *}$ & 0.18793 \\
\hline
\end{tabular}

Panel B:

Taiwanese ADR

Taiwanese underlying securities

\begin{tabular}{lcccccccc} 
& \multicolumn{2}{c}{ Opening prices } & \multicolumn{2}{c}{ Closing prices } & \multicolumn{2}{c}{ Opening prices } & \multicolumn{2}{c}{ Closing prices } \\
\cline { 2 - 9 } & Price & First & Price & First & Price & First & Price & First \\
& level & difference & Level & difference & level & difference & level & difference \\
\hline ADF & -2.47219 & $-58.98046^{* * * *}$ & -2.49726 & $-62.76781^{* * *}$ & -2.06722 & $-31.76760^{* * * *}$ & -2.07948 & $-55.93409^{* * * *}$ \\
PP & -2.44063 & $-59.00610^{* * * *}$ & -2.43615 & $-62.94428^{* * *}$ & -2.04748 & $-55.30705^{* * *}$ & -2.11896 & $-55.92443^{* * *}$ \\
KPSS & $1.86427^{* * * *}$ & 0.30780 & $1.87124^{* * *}$ & 0.32046 & $4.15384^{* * *}$ & 0.21484 & $4.15824^{* * *}$ & 0.21249 \\
\hline
\end{tabular}

Notes:

1. ADF, PP, and KPSS are the test statistics for the Augmented Dickey-Fuller (Said and Dickey, 1984), the Phillips-Perron (Phillips and Perron, 1988), and the Kwiatkowski-Phillips-Schmidt-Shin (Kwiatkowski et al., 1992) unit root tests, respectively.

2. The price levels are the logarithms of the opening prices and closing prices for the ADRs and their underlying securities, respectively.

3. *** stands for significance at the $1 \%$ level.

Moreover, the Johansen (1988) and Engle and Granger (1987) cointegration tests are exploited to examine whether the long-run equilibrium relationship exists between the prices of the ADRs and their underlying foreign securities. 
As presented in Panels A and B of Table 2, the opening prices of the ADRs and the same-period closing prices of their underlying foreign securities are cointegrated of rank one, and the opening prices of the underlying foreign securities and the prior-period closing prices of their ADRs are also cointegrated for the Chinese firms and Taiwanese firms, respectively, after considering the differences in time zones between the ADRs (in US) and their underlying foreign securities (in Asia). Therefore, the error-correction term would be considered into the models to account for the long-run equilibrium relationship between the ADRs and their underlying foreign securities.

Table 2. Results of the cointegration tests to examine the long-term equilibrium relationship

\begin{tabular}{lcc}
\hline Panel A: Cointegration test results for $\boldsymbol{e c a}$ & Chinese firms & Taiwanese firms \\
\hline Johansen test $\left(\boldsymbol{\lambda}_{\text {Trace }}\right)$ & $14.50281^{*}$ & $25.29067^{* * *}$ \\
$\gamma=\mathbf{0}$ & 0.29603 & 1.93810 \\
$\gamma \leqq \mathbf{1}$ & & \\
Johansen test $\left(\boldsymbol{\lambda}_{\text {Max-Eigenvalue }}\right)$ & $14.18677^{*}$ & $23.35257^{* * *}$ \\
$\gamma=\mathbf{0}$ & 0.29603 & 1.93810 \\
$\gamma \leqq \mathbf{1}$ & & $-4.59174^{* * *}$ \\
Engle-Granger two-step test & $-3.34022^{* *}$ & $-4.68016^{* * *}$ \\
ADF & $-2.98870^{* *}$ & \\
PP & & Taiwanese firms \\
\hline Panel B: Cointegration test results for ecs & \\
& Chinese firms & $23.25451^{* * *}$ \\
\hline Johansen test $\left(\boldsymbol{\lambda}_{\text {Trace }}\right)$ & & 2.27198 \\
$\gamma=\mathbf{0}$ & $14.93443^{*}$ & \\
$\gamma \leqq \mathbf{1}$ & 0.79628 & $20.98252^{* * *}$ \\
Johansen test $\left(\boldsymbol{\lambda}_{\text {Max-Eigenvalue }}\right)$ & & 2.27198 \\
$\gamma=\mathbf{0}$ & $14.12816^{*}$ & $-2.93764^{* *}$ \\
$\gamma \leqq \mathbf{1}$ & 0.79628 & $-2.88315^{* *}$ \\
Engle-Granger two-step test & & \\
ADF & $-2.86918^{* *}$ & \\
PP & $-2.57843^{* *}$ & \\
\hline
\end{tabular}

Notes:

1. For the Johansen cointegration tests (Johansen, 1988), the null hypothesis $\gamma \leqq 1$ indicates that the number of cointegrating vector is less than or equal to one, while the null hypothesis $\gamma=0$ indicates that the number of cointegrating vector is zero.

2. The Engle and Granger two-step tests (Engle and Granger, 1987) are used to examine the cointegration relationship between the prices of the ADRs and their underlying foreign securities. The Augmented Dickey-Fuller (ADF) and Phillips-Perron (PP) unit root tests are used to examine the residuals from the first-step model to test the null hypothesis of no cointegration.

3. The eca represents the error-correction term between the opening prices of the ADRs and the same-period closing prices of their underlying foreign securities, while the ecs is the error-correction term between the opening prices of the underlying foreign securities and the prior-period closing prices of their ADRs, after considering the differences in time zones between the ADRs and their underlying foreign securities.

4. *, **, and $* * *$ stand for significance at the $10 \%, 5 \%$, and $1 \%$ level, respectively.

Table 3 presents the descriptive statistics of the overnight returns (the log-difference between the opening prices and prior-period closing prices) and the daytime returns (the log-difference between the closing prices and same-period 
opening prices) of the ADRs and their underlying foreign securities for the Chinese firms and Taiwanese firms. It shows that the standard deviations of the daytime returns appear to be greater than those of the overnight returns for Chinese and Taiwanese ADRs and their underlying securities, respectively. The Jarque-Bera test statistics demonstrate that the daytime returns and overnight returns of the ADRs and their underlying securities do not follow the normal distribution. The distributions of the daytime returns and overnight returns seem to be heavy-tailed and non-normal, as suggested by the skewness and kurtosis test statistics.

Table 3. Descriptive statistics of the overnight returns and daytime returns for the ADRs and their underlying foreign securities

\begin{tabular}{lcccc}
\hline Panel A: & \multicolumn{2}{c}{ Chinese ADRs } & \multicolumn{2}{c}{ Chinese underlying securities } \\
& Overnight return & Daytime return & Overnight return & Daytime return \\
\hline Mean & $0.017140 \%$ & $0.010519 \%$ & $-0.064823 \%$ & $0.081795 \%$ \\
Median & $0.055793 \%$ & $0.043962 \%$ & $-0.001015 \%$ & $0.020374 \%$ \\
Std. Dev. & $1.310647 \%$ & $1.672635 \%$ & $0.878251 \%$ & $1.695026 \%$ \\
Skewness & $-0.425981^{* * *}$ & $0.436315^{* * *}$ & $-0.480718^{* * *}$ & $0.216295^{* * *}$ \\
Kurtosis & $8.483452^{* * *}$ & $13.024172^{* * *}$ & $17.610245^{* * *}$ & $6.784368^{* * *}$ \\
J-B & $4389.4402^{* * * *}$ & $14431.7034^{* * *}$ & $30558.5982^{* * *}$ & $2068.0765^{* * *}$ \\
\end{tabular}

Panel B:

Taiwanese ADRs

\begin{tabular}{lcccc} 
& Overnight return & Daytime return & Overnight return & Daytime return \\
\hline Mean & $0.015753 \%$ & $-0.001142 \%$ & $0.057865 \%$ & $-0.036954 \%$ \\
Median & $0.041060 \%$ & $-0.011017 \%$ & $0.066841 \%$ & $-0.021348 \%$ \\
Std. Dev. & $1.252463 \%$ & $1.469807 \%$ & $1.182374 \%$ & $1.227691 \%$ \\
Skewness & $-0.467785^{* * *}$ & $0.362379^{* * *}$ & $-0.200535^{* * *}$ & 0.047058 \\
Kurtosis & $15.601320^{* * *}$ & $9.542798^{* * *}$ & $9.251541^{* * *}$ & $4.956122^{* * *}$ \\
J-B & $23085.4122^{* * *}$ & $6265.2990^{* * *}$ & $5673.8291^{* * *}$ & $554.5163^{* * *}$ \\
\hline
\end{tabular}

Notes:

1. Mean, Median, Std. Dev., Skewness, and Kurtosis are the sample mean, median, standard deviation, skewness, and kurtosis of the overnight and daytime return distributions, respectively.

2. The Jarque-Bera (J-B) statistics are used to examine whether returns follow the normal distribution.

3. *** stands for significance at the $1 \%$ level.

Moreover, the results of the Ljung-Box Q statistics in Table 4, examining the autocorrelation in the time series of the standardized residuals and squared standardized residuals, suggest that there are volatility-clustering effects for the ADRs and their underlying foreign securities of Chinese firms and Taiwanese firms. In addition, the results for testing the existence of heteroskedasticity are demonstrated in Panels A and B of Table 5. The LM and joint LM test statistics examining the squared residuals indicate that the presence of ARCH effects and joint ARCH effects in the volatility of the daytime returns and overnight returns for the ADRs and their underlying securities.

Furthermore, the Engle and $\mathrm{Ng}$ (1993) diagnostic tests are employed to explore the asymmetries in the conditional variance of the daytime returns and overnight returns for the ADRs and their underlying securities. The test results of the squared standardized residuals in Panels A and B of Table 6 show that the diagnostic test statistics especially those testing the negative size bias are significant. It reveals the presence of the leverage effect. The negative shocks (innovations) may have a greater impact on the volatility. Therefore, the asymmetric responses in the conditional volatility should be considered in the models. 
Table 4. Autocorrelation of the overnight and daytime returns for the ADRs and their underlying foreign securities

\section{Panel A:}

Chinese ADRs

\begin{tabular}{lcccc} 
& Overnight return & Daytime return & Overnight return & Daytime return \\
\hline $\mathrm{LB}(10)$ & $17.5021^{*}$ & $58.4436^{* * *}$ & $57.0862^{* * *}$ & $28.4871^{* * * *}$ \\
$\mathrm{LB}(20)$ & $35.7636^{* * *}$ & $82.3894^{* * *}$ & $71.1283^{* * *}$ & $55.4236^{* * *}$ \\
$\mathrm{LB}^{2}(10)$ & $799.7513^{* * *}$ & $1547.4120^{* * *}$ & 10.8749 & $542.3620^{* * * *}$ \\
$\mathrm{LB}^{2}(20)$ & $1192.4941^{* * *}$ & $2616.8417^{* * *}$ & 13.8016 & $962.1504^{* * *}$ \\
\hline
\end{tabular}

\section{Panel B:}

Taiwanese ADRs

\begin{tabular}{lcccc} 
& Overnight return & Daytime return & Overnight return & Daytime return \\
\hline $\mathrm{LB}(10)$ & $47.5820^{* * *}$ & 8.1682 & $47.4903^{* * *}$ & $61.7184^{* * *}$ \\
$\mathrm{LB}(20)$ & $64.0631^{* * *}$ & $42.6254^{* * *}$ & $73.1536^{* * *}$ & $69.5231^{* * *}$ \\
$\mathrm{LB}^{2}(10)$ & $579.3684^{* * *}$ & $1644.1317^{* * *}$ & $1025.3537^{* * *}$ & $638.1093^{* * *}$ \\
$\mathrm{LB}^{2}(20)$ & $794.3075^{* * *}$ & $3202.1281^{* * *}$ & $1413.9274^{* * *}$ & $1141.5162^{* * * *}$ \\
\hline
\end{tabular}

Notes:

1. $\operatorname{LB}(10), \operatorname{LB}(20), \operatorname{LB}^{2}(10)$, and $\operatorname{LB}^{2}(20)$ are the Ljung-Box $\mathrm{Q}$ statistics examining the autocorrelation in the time series of the standardized residuals and squared standardized residuals, respectively, with time lags of 10 and 20 periods.

2. *,**, and *** stand for significance at the $10 \%, 5 \%$, and $1 \%$ level, respectively.

Table 5. Results of Lagrange Multiplier (LM) tests to examine the heteroskedasticity

Panel A: Chinese firms

\begin{tabular}{lcccccc} 
& \multicolumn{3}{c}{ Overnight returns } & \multicolumn{3}{c}{ Daytime returns } \\
\cline { 2 - 7 } & \multirow{2}{*}{ ADRs } & $\begin{array}{l}\text { Underlying } \\
\text { securities }\end{array}$ & Joint LM $\mathbf{L M}_{\text {Night }}$ & ADRs & $\begin{array}{l}\text { Underlying } \\
\text { securities }\end{array}$ & Joint LM Day \\
\hline $\mathrm{LM}(10)$ & $410.9750^{* * * *}$ & $41.4302^{* * *}$ & $1703.3915^{* * *}$ & $172.8316^{* *}$ & $118.6798^{* * *}$ & $1249.2754^{* * *}$ \\
$\mathrm{LM}(20)$ & $177.1403^{* * *}$ & $130.9275^{* * *}$ & $1449.8107^{* * *}$ & $136.5864^{* *}$ & $124.2031^{* * *}$ & $1583.9236^{* * *}$ \\
\hline
\end{tabular}

Panel B: Taiwanese firms

\begin{tabular}{|c|c|c|c|c|c|c|}
\hline & \multicolumn{3}{|c|}{ Overnight returns } & \multicolumn{3}{|c|}{ Daytime returns } \\
\hline & ADRs & $\begin{array}{l}\text { Underlying } \\
\text { securities }\end{array}$ & Joint $\mathbf{L} \mathbf{M}_{\text {Night }}$ & ADRs & $\begin{array}{l}\text { Underlying } \\
\text { securities }\end{array}$ & Joint $\mathbf{L} \mathbf{M}_{\text {Day }}$ \\
\hline LM(10) & $110.1781^{* * *}$ & $230.7228^{* * * *}$ & $1916.6832^{* * * *}$ & $414.8831^{* *}$ & $173.1278^{* * * *}$ & $2128.1876^{* * *}$ \\
\hline $\mathrm{LM}(20)$ & $153.0327^{* * *}$ & $92.1793^{* * *}$ & $1179.0551^{* * *}$ & $231.6284^{* *}$ & $91.3586^{* * *}$ & $1261.7421^{* * *}$ \\
\hline
\end{tabular}

Notes:

1. $\mathrm{LM}(10)$ and $\mathrm{LM}(20)$ are the Lagrange Multiplier (LM) test statistics examining the squared residuals with lags of 10 and 20 periods to explore the ARCH effects in the volatility of the daytime returns and overnight returns of the ADRs and their underlying securities, respectively.

2. Joint $\mathrm{LM}_{\mathrm{Night}}(10)$ and Joint $\mathrm{LM}_{\mathrm{Night}}(20)$ are the joint $\mathrm{LM}$ test statistics examining the squared residuals with lags of 10 and 20 periods to explore the joint ARCH effects in the volatility of the overnight returns of the ADRs and their underlying securities, and the Joint $\operatorname{LM}_{\text {Day }}(10)$ and Joint $\operatorname{LM}_{\text {Day }}(20)$ are the joint $\mathrm{LM}$ test statistics examining the squared residuals with lags of 10 and 20 periods to explore the joint ARCH effects in the volatility of the daytime returns of the ADRs and their underlying securities.

3. ** and $* * *$ stand for significance at the $5 \%$ and $1 \%$ level, respectively. 
Table 6. Diagnostic tests to assess the asymmetries in the conditional volatility

Panel A: Chinese firms

\begin{tabular}{lcccc} 
& \multicolumn{2}{c}{ Overnight returns } & \multicolumn{2}{c}{ Daytime returns } \\
\cline { 2 - 5 } & ADRs & $\begin{array}{l}\text { Underlying } \\
\text { securities }\end{array}$ & ADRs & $\begin{array}{c}\text { Underlying } \\
\text { securities }\end{array}$ \\
\hline Sign Bias & 1.0521 & -0.5776 & 1.4397 & 0.5087 \\
Negative Size Bias & $-9.8357^{* * *}$ & $-7.8693^{* * *}$ & $-9.6258^{* * *}$ & $-6.3027^{* * *}$ \\
Positive Size Bias & $4.8219^{* * *}$ & $5.4428^{* * *}$ & $7.5416^{* * *}$ & $4.1329^{* * *}$ \\
Joint Test & $57.9462^{* * *}$ & $37.8762^{* * *}$ & $75.3108^{* * *}$ & $27.6435^{* * *}$
\end{tabular}

Panel B: Taiwanese firms

Overnight returns

Daytime returns

\begin{tabular}{lcccc} 
& ADRs & $\begin{array}{l}\text { Underlying } \\
\text { securities }\end{array}$ & ADRs & $\begin{array}{l}\text { Underlying } \\
\text { securities }\end{array}$ \\
\hline Sign Bias & $3.1463^{* * *}$ & $1.7236^{*}$ & $1.6821^{*}$ & 1.2089 \\
Negative Size Bias & $-10.7186^{* * *}$ & $-10.1608^{* * *}$ & $-11.6045^{* * *}$ & $-6.0278^{* * *}$ \\
Positive Size Bias & $1.8892^{*}$ & $4.5413^{* * *}$ & $3.8502^{* * *}$ & $2.0562^{* *}$ \\
Joint Test & $47.8953^{* * *}$ & $59.8754^{* * *}$ & $71.6318^{* * *}$ & $19.8624^{* * *}$ \\
\hline
\end{tabular}

Notes:

1. This table presents the volatility specification tests of Engle and $\mathrm{Ng}$ (1993), examining the squared standardized residuals to explore the asymmetries in the conditional variance of the daytime returns and overnight returns for the ADRs and their underlying securities.

2. The diagnostic tests include the sign bias test (SBT), the negative size bias test (NSBT), the positive size bias test (PSBT), and the joint test (JT).

3. *,**, and $* * *$ stand for significance at the $10 \%, 5 \%$, and $1 \%$ level, respectively.

\subsection{The Information Transmission of Returns and Volatilities for the ADRs and Their Underlying Foreign Securities}

This study employs the two-stage bivariate GJR-GARCH models to analyze the information transmission dynamics of risk and returns for the Chinese and Taiwanese ADRs and their underlying foreign securities. In the first stage, we estimate the unexpected returns (shocks) that cannot be predicted based on the information from the prior overnight returns of the ADRs and their underlying securities, after the prior-period markets close until the current-period markets open. In the second stage, we further examine the potential asymmetric reactions in the means and volatilities of the daytime returns for the ADRs and their underlying securities, after the current-period markets open until the current-period markets close, by taking into account the exogenous influence from the additional information of the overnight returns on the ADRs and their underlying securities as well. The two-stage bivariate GJR-GARCH models not only consider the possible interdependence between the overnight returns and the daytime returns of both the ADRs and their underlying securities, but also reflect the information transmission dynamics of returns and volatilities between the ADRs and their underlying foreign securities.

The final results for the second stage of the models are reported in Table 7. In Panel A of Table 7, the estimation results of the mean equations indicate that after taking into account the information from their underlying foreign securities, the lagged daytime returns of ADRs have a significantly negative impact on their own daytime returns for Chinese and Taiwanese ADRs, respectively $\left(\phi_{A D^{+}, 1}<0\right.$ and $\left.\phi_{A D^{-}, 1}<0\right)$. The coefficient $\phi_{A D^{-, 1}}$ is even greater than $\phi_{A D^{+}, 1}$ in absolute magnitude, suggesting that the speed of mean reversion or price adjustment towards their intrinsic value is faster following the negative information than the positive information. However, the lagged daytime returns of Taiwanese ADRs have a significantly positive influence on the daytime returns of Taiwanese underlying securities $\left(\psi_{A D^{+}, 1}>0\right.$ and $\left.\psi_{A D^{-}, 1}>0\right)$. The coefficients of the error-correction terms are significantly negative for the daytime returns of Taiwanese ADRs $\left(\gamma_{A D}<0\right)$ and Chinese underlying securities $\left(\gamma_{S D}<0\right)$, respectively. It reveals that a long-term equilibrium relationship exists between the opening prices of Taiwanese ADRs and the same-period 
closing prices of Taiwanese underlying securities. Similarly, it also indicates that there is a cointegration relationship between the opening prices of Chinese underlying securities and the prior-period closing prices of Chinese ADRs, after considering the differences in time zones between the ADRs and their underlying foreign securities. Furthermore, we find that the unanticipated shocks from the overnight returns of the underlying securities have a significantly positive impact on the same-period daytime returns of their ADRs for both Chinese and Taiwanese firms $\left(\theta_{S N, 0}>0\right)$. However, the unexpected innovations from the prior-period overnight returns of the ADRs have a significantly positive effect on the daytime returns of their underlying securities only for Taiwanese firms $\left(\lambda_{A N, 1}>0\right)$. These clearly indicate that the information transmission of returns between ADRs and their underlying securities is bi-directional for Taiwanese securities, but uni-directional (from the underlying securities to their ADRs) for Chinese securities.

In Panel B of Table 7, the estimation results of the conditional variance equations indicate that the volatilities of the daytime returns for Chinese and Taiwanese ADRs and the underlying securities are affected by their own lagged volatilities and lagged squared residuals. The results also reveal that the conditional volatilities of the daytime returns for Chinese and Taiwanese ADRs display asymmetric responses to different types of information (positive and negative information). The impacts on the volatilities of the daytime returns from the negative shocks would be greater than those from the positive shocks for Chinese and Taiwanese ADRs $\left(\delta_{A D 1}>0\right)$, respectively. Moreover, the conditional volatility of the daytime returns of Taiwanese underlying securities (Taiwanese ADRs) is positively affected by the unexpected surprises from the daytime returns of Taiwanese ADRs (Taiwanese underlying securities), $\alpha_{S D, 3}>0\left(\alpha_{A D, 3}>0\right)$. Besides, our empirical results also show that the unexpected shocks from the overnight returns of the underlying securities have a significantly positive impact on the same-period conditional volatilities of the daytime returns for both Chinese and Taiwanese ADRs $\left(\beta_{S N, 0}>0\right)$. In addition, the unanticipated innovations from the prior-period overnight returns of the ADRs also have a significantly positive influence on the conditional volatilities of the daytime returns of their underlying securities in Taiwan $\left(\omega_{A N, 1}>0\right)$. These indicate that the volatility spillover between ADRs and their underlying securities is also bi-directional for Taiwanese securities, but uni-directional (from the underlying securities to their ADRs) for Chinese securities.

Furthermore, although the mean and volatility spillovers between ADRs and their underlying securities are bi-directional for Taiwanese securities, there are different degrees of impacts from different directions. Our results find that the estimated coefficients of $\lambda_{A N, 1}>\theta_{S N, 0}$ and $\omega_{A N, 1}>\beta_{S N, 0}$ for Taiwanese firms, as shown in Panels A and $\mathrm{B}$ of Table 7. It implies that the influence from the unexpected overnight returns of Taiwanese ADRs on the means and volatilities of daytime returns of their underlying securities is slightly greater than the impact from the unexpected overnight returns of Taiwanese underlying securities on the means and volatilities of daytime returns of their ADRs. In other words, the information transmission from Taiwanese ADRs to their underlying securities is slightly stronger than that from Taiwanese underlying securities to their ADRs. While the international center hypothesis and the home bias hypothesis are both supported in this case, the effect of the international center hypothesis seems to be greater for the Taiwanese securities cross-listed in US stock markets. On the other hand, our empirical results reveal that the information transmission from Chinese underlying securities to their ADRs is much stronger than that from Chinese ADRs to their underlying securities $\left(\theta_{S N, 0}>\lambda_{A N, 1}\right.$ and $\left.\beta_{S N, 0}>\omega_{A N, 1}\right)$. The results tend to support the home bias hypothesis for the Chinese securities cross-listed in US stock markets.

Moreover, the following hypotheses are further examined by using the likelihood ratio tests to analyze whether the mean daytime returns for ADRs and their underlying securities exhibit asymmetric reactions to specific positive and negative information of the prior-period daytime returns of ADRs and their underlying securities.

$\left(\mathrm{H}_{01}\right) \phi_{A D^{+}, 1}=\phi_{A D^{-}, 1}, \phi_{A D^{+}, 2}=\phi_{A D^{-, 2}}$. There is no asymmetric effect on the daytime returns of ADRs from the positive and negative information of the prior-period daytime returns of ADRs themselves.

$\left(\mathrm{H}_{02}\right) \quad \phi_{S D^{+}, 1}=\phi_{S D^{-, 1}}, \phi_{S D^{+}, 2}=\phi_{S D^{-, 2}}$. There is no asymmetric effect on the daytime returns of ADRs from the positive and negative information of the prior-period daytime returns of their underlying securities.

$\left(\mathrm{H}_{03}\right) \psi_{S D^{+}, 1}=\psi_{S D^{-}, 1}, \psi_{S D^{+}, 2}=\psi_{S D^{-}, 2}$. There is no asymmetric effect on the daytime returns of ADRs' underlying securities from the positive and negative information of the prior-period daytime returns of the underlying securities themselves.

$\left(\mathrm{H}_{04}\right) \psi_{A D^{+}, 1}=\psi_{A D^{-1}, 1}, \psi_{A D^{+}, 2}=\psi_{A D^{-, 2}}$. There is no asymmetric effect on the daytime returns of ADRs' underlying securities from the positive and negative information of the prior-period daytime returns of their ADRs. 
Table 7. Estimation results for the two-stage bivariate GJR-GARCH models

Panel A: Estimation results of the mean equations

\begin{tabular}{|c|c|c|c|c|c|c|}
\hline \multirow{2}{*}{$\begin{array}{l}\text { Model } \\
\text { parameters }\end{array}$} & \multicolumn{3}{|c|}{ Chinese firms } & \multicolumn{3}{|c|}{ Taiwanese firms } \\
\hline & $\begin{array}{l}\text { Parameter } \\
\text { estimates }\end{array}$ & $\begin{array}{l}\text { Standard } \\
\text { errors }\end{array}$ & T-statistics & $\begin{array}{l}\text { Parameter } \\
\text { estimates }\end{array}$ & $\begin{array}{l}\text { Standard } \\
\text { errors }\end{array}$ & T-statistics \\
\hline$\phi_{A D, 0}$ & 0.02145 & 0.02531 & 0.84749 & -0.02110 & 0.03842 & -0.54924 \\
\hline$\phi_{A D^{+}, 1}$ & $-0.06092^{* *}$ & 0.02928 & -2.08066 & $-0.09579^{* * *}$ & 0.02879 & -3.32699 \\
\hline$\phi_{A D^{+}, 2}$ & 0.02656 & 0.02682 & 0.99031 & 0.00891 & 0.02677 & 0.33276 \\
\hline$\phi_{A D^{-}, 1}$ & $-0.10592^{* * *}$ & 0.02796 & -3.78827 & $-0.11845^{* * *}$ & 0.02664 & -4.44638 \\
\hline$\phi_{A D^{-}, 2}$ & -0.04459 & 0.02949 & -1.51170 & 0.01029 & 0.02913 & 0.35322 \\
\hline$\phi_{S D^{+}, 1}$ & $0.03976^{*}$ & 0.02404 & 1.65384 & $0.06648^{* * *}$ & 0.02316 & 2.87085 \\
\hline$\phi_{S D^{+}, 2}$ & 0.02516 & 0.02907 & 0.86532 & $0.03978^{* *}$ & 0.02014 & 1.97491 \\
\hline$\phi_{S D^{-}, 1}$ & $0.07700^{* * * *}$ & 0.02939 & 2.61989 & $0.09406^{* * *}$ & 0.02849 & 3.30139 \\
\hline$\phi_{S D^{-}, 2}$ & 0.02758 & 0.03148 & 0.87607 & 0.02437 & 0.02558 & 0.95264 \\
\hline$\gamma_{A D}$ & -0.00163 & 0.00165 & -0.98506 & $-0.00250^{* * *}$ & 0.00080 & -3.13345 \\
\hline$\theta_{A N, 0}$ & $0.10392^{* * *}$ & 0.01159 & 8.96317 & $0.07882^{* * *}$ & 0.02148 & 3.67006 \\
\hline$\theta_{A N, 1}$ & -0.01518 & 0.01203 & -1.26233 & $-0.04693^{*}$ & 0.02441 & -1.92300 \\
\hline$\theta_{S N, 0}$ & $0.06697^{* *}$ & 0.02783 & 2.40695 & $0.04522^{* *}$ & 0.02031 & 2.22669 \\
\hline$\theta_{S N, 1}$ & 0.01877 & 0.02415 & 0.77715 & -0.00149 & 0.02239 & -0.06651 \\
\hline$\psi_{S D, 0}$ & 0.03004 & 0.04027 & 0.74604 & -0.01508 & 0.03643 & -0.41387 \\
\hline$\psi_{S D^{+}, 1}$ & $0.05030^{* *}$ & 0.02418 & 2.08043 & -0.01195 & 0.02776 & -0.43046 \\
\hline$\psi_{S D^{+}, 2}$ & $0.06141^{* *}$ & 0.02554 & 2.40451 & $-0.03985^{*}$ & 0.02389 & -1.66764 \\
\hline$\psi_{S D^{-}, 1}$ & $-0.15488^{* * *}$ & 0.02827 & -5.47776 & $-0.04676^{* *}$ & 0.02359 & -1.98237 \\
\hline$\psi_{S D^{-}, 2}$ & $-0.08894^{* * *}$ & 0.02831 & -3.14182 & $-0.06285^{* *}$ & 0.02736 & -2.29752 \\
\hline$\psi_{A D^{+}, 1}$ & 0.00979 & 0.01285 & 0.76161 & $0.07962^{* * *}$ & 0.02903 & 2.74264 \\
\hline$\psi_{A D^{+}, 2}$ & 0.01028 & 0.01257 & 0.81792 & $0.05817^{* *}$ & 0.02710 & 2.14684 \\
\hline$\psi_{A D^{-}, 1}$ & $0.05011^{* *}$ & 0.01980 & 2.53089 & $0.05000^{* * *}$ & 0.02502 & 1.99816 \\
\hline$\psi_{A D^{-}, 2}$ & 0.01772 & 0.01523 & 1.16387 & 0.00489 & 0.02482 & 0.19685 \\
\hline$\gamma_{S D}$ & $-0.00379^{* * *}$ & 0.00112 & -3.39808 & -0.00144 & 0.00165 & -0.87504 \\
\hline$\lambda_{A N, 1}$ & 0.02777 & 0.01697 & 1.63648 & $0.07362^{* * *}$ & 0.02561 & 2.87495 \\
\hline$\lambda_{A N, 2}$ & 0.02240 & 0.01628 & 1.37593 & 0.02062 & 0.01771 & 1.16432 \\
\hline$\lambda_{S N, 0}$ & $0.18337^{* * *}$ & 0.03753 & 4.88612 & $0.19082^{* * *}$ & 0.02273 & 8.39329 \\
\hline$\lambda_{S N, 1}$ & -0.01168 & 0.02267 & -0.51512 & 0.01435 & 0.02051 & 0.69993 \\
\hline
\end{tabular}




\section{Panel B: Estimation results of the variance equations}

\begin{tabular}{lcccccc}
\hline Model & \multicolumn{3}{c}{ Chinese firms } & \multicolumn{3}{c}{ Taiwanese firms } \\
\cline { 2 - 7 } parameters & $\begin{array}{l}\text { Parameter } \\
\text { estimates }\end{array}$ & $\begin{array}{l}\text { Standard } \\
\text { errors }\end{array}$ & T-statistics & $\begin{array}{l}\text { Parameter } \\
\text { estimates }\end{array}$ & $\begin{array}{l}\text { Standard } \\
\text { errors }\end{array}$ & T-statistics \\
\hline$\alpha_{A D, 0}$ & $0.01363^{* * *}$ & 0.00399 & 3.41449 & $0.00608^{*}$ & 0.00352 & 1.72829 \\
$\alpha_{A D, 1}$ & $0.89653^{* * *}$ & 0.01311 & 68.38006 & $0.94413^{* * *}$ & 0.01726 & 54.69597 \\
$\alpha_{A D, 2}$ & $0.03108^{* * *}$ & 0.01037 & 2.99676 & $0.02085^{* *}$ & 0.01059 & 1.96836 \\
$\delta_{A D 1}$ & $0.09306^{* * *}$ & 0.01759 & 5.29166 & $0.03485^{* * *}$ & 0.01067 & 3.26471 \\
$\alpha_{A D, 3}$ & 0.00282 & 0.00197 & 1.43249 & $0.00927^{*}$ & 0.00558 & 1.66032 \\
$\delta_{A D 2}$ & 0.00481 & 0.00309 & 1.55381 & 0.00012 & 0.01216 & 0.00968 \\
$\beta_{A N, 0}$ & $0.03947^{* * *}$ & 0.00838 & 4.70682 & $0.15233^{* * *}$ & 0.02769 & 5.50197 \\
$\beta_{A N, 1}$ & $-0.03041^{* * *}$ & 0.00763 & -3.98402 & $-0.14058^{* * *}$ & 0.02722 & -5.16543 \\
$\beta_{S N, 0}$ & $0.07975^{* * *}$ & 0.02703 & 2.95065 & $0.03702^{*}$ & 0.01985 & 1.86502 \\
$\beta_{S N, 1}$ & $-0.07586^{* * *}$ & 0.02588 & -2.93139 & $-0.03648^{*}$ & 0.02079 & -1.75467 \\
\hline$\alpha_{S D, 0}$ & $0.01846^{* *}$ & 0.00726 & 2.54443 & $0.01853^{* * *}$ & 0.00676 & 2.74115 \\
$\alpha_{S D, 1}$ & $0.91704^{* * *}$ & 0.01260 & 72.77282 & $0.93668^{* * *}$ & 0.01239 & 75.59018 \\
$\alpha_{S D, 2}$ & $0.07408^{* * *}$ & 0.01359 & 5.45209 & $0.02784^{* * *}$ & 0.00812 & 3.42802 \\
$\delta_{S D 1}$ & $0.01798^{*}$ & 0.01064 & 1.68982 & $0.01270^{*}$ & 0.00768 & 1.65252 \\
$\alpha_{S D, 3}$ & -0.00192 & 0.00488 & -0.39357 & $0.01181^{* *}$ & 0.00596 & 1.98067 \\
$\delta_{S D 2}$ & 0.01901 & 0.01424 & 1.33529 & 0.00179 & 0.00470 & 0.38064 \\
$\omega_{A N, 1}$ & 0.01879 & 0.01293 & 1.45257 & $0.04917^{* *}$ & 0.02502 & 1.96479 \\
$\omega_{A N, 2}$ & -0.01339 & 0.01287 & -1.04098 & $-0.04662^{*}$ & 0.02465 & -1.89110 \\
$\omega_{S N, 0}$ & $0.48706^{* * *}$ & 0.12229 & 3.98277 & $0.09272^{* * *}$ & 0.02081 & 4.45563 \\
$\omega_{S N, 1}$ & $-0.43439^{* * *}$ & 0.11559 & -3.75796 & $-0.08781^{* * *}$ & 0.02064 & -4.25385 \\
\hline & & & & & &
\end{tabular}

Notes:

1. *, **, and *** stand for significance at the $10 \%, 5 \%$, and $1 \%$ level, respectively.

2. The empirical models in the second stage are described in Section 3.4 (equations (8) (12)) and also shown below:

$$
\begin{aligned}
R A D_{t}= & \phi_{A D, 0}+\sum_{i=1}^{A 2} \phi_{A D^{+}, i} R A D_{t-i}^{+}+\sum_{i=1}^{A 2} \phi_{A D^{-}, i} R A D_{t-i}^{-}+\sum_{j=1}^{S 2} \phi_{S D^{+}, j} R S D_{t-j}^{+}+\sum_{j=1}^{S 2} \phi_{S D^{-}, j} R S D_{t-j}^{-} \\
+ & \sum_{i=0}^{m} \theta_{A N, i} e_{A N, t-i}+\sum_{j=0}^{n} \theta_{S N, j} e_{S N, t-j}+\gamma_{A D} e c a_{t-1}+\varepsilon_{A D, t} \\
R S D_{t}= & \psi_{S D, 0}+\sum_{j=1}^{S 2} \psi_{S D^{+}, j} R S D_{t-j}^{+}+\sum_{j=1}^{S 2} \psi_{S D^{-}, j} R S D_{t-j}^{-}+\sum_{i=1}^{A 2} \psi_{A D^{+}, i} R A D_{t-i}^{+}+\sum_{i=1}^{A 2} \psi_{A D^{-}, i} R A D_{t-i}^{-} \\
+ & \sum_{i=1}^{m} \lambda_{A N, i} e_{A N, t-i}+\sum_{j=0}^{n} \lambda_{S N, j} e_{S N, t-j}+\gamma_{S D} e c s_{t-1}+\varepsilon_{S D, t} \\
h_{A D, t}=\alpha_{A D, 0} & +\alpha_{A D, 1} h_{A D, t-1}+\alpha_{A D, 2}\left(\varepsilon_{A D, t-1}\right)^{2}+\delta_{A D 1} I_{t-1}\left(\varepsilon_{A D, t-1}\right)^{2}+\alpha_{A D, 3}\left(\varepsilon_{S D, t-1}\right)^{2} \\
& +\delta_{A D 2} I_{t-1}\left(\varepsilon_{S D, t-1}\right)^{2}+\sum_{i=0}^{r 2} \beta_{A N, i}\left(e_{A N, t-i}\right)^{2}+\sum_{j=0}^{r 3} \beta_{S N, j}\left(e_{S N, t-j}\right)^{2} \\
h_{S D, t}=\alpha_{S D, 0} & +\alpha_{S D, 1} h_{S D, t-1}+\alpha_{S D, 2}\left(\varepsilon_{S D, t-1}\right)^{2}+\delta_{S D 1} I_{t-1}\left(\varepsilon_{S D, t-1}\right)^{2}+\alpha_{S D, 3}\left(\varepsilon_{A D, t-1}\right)^{2} \\
& +\delta_{S D 2} I_{t-1}\left(\varepsilon_{A D, t-1}\right)^{2}+\sum_{i=1}^{r 2} \omega_{A N, i}\left(e_{A N, t-i}\right)^{2}+\sum_{j=0}^{r 3} \omega_{S N, j}\left(e_{S N, t-j}\right)^{2}
\end{aligned}
$$




$$
h_{A D, S D, t}=\rho_{2} \sqrt{h_{A D, t} h_{S D, t}}
$$

The results of the likelihood ratio tests are reported in Table 8. Since the null hypothesis $\mathrm{H}_{01}$ is rejected for the Chinese firms, it indicates that the positive and negative information of the prior-period daytime returns of Chinese ADRs have significant asymmetric influences on the daytime returns of Chinese ADRs themselves. While the $\mathrm{H}_{03}$ is also rejected for the Chinese and Taiwanese firms, it implies that the good news and bad news of the prior-period daytime returns of Chinese and Taiwanese underlying securities also have substantial asymmetric impacts on the daytime returns of Chinese and Taiwanese underlying securities themselves.

In addition, the following hypotheses are further examined to analyze the information transmission and spillover effects from the unanticipated shocks of the overnight returns to the means and volatilities of the daytime returns for ADRs and their underlying securities.

$\left(\mathrm{H}_{05}\right) \theta_{A N, 0}=\theta_{A N, 1}=0$. The unexpected surprises from the overnight returns of ADRs have no impact on the daytime returns of ADRs themselves.

$\left(\mathrm{H}_{06}\right) \quad \theta_{S N, 0}=\theta_{S N, 1}=0$. The unexpected surprises from the overnight returns of the underlying securities have no impact on the daytime returns of their ADRs.

$\left(\mathrm{H}_{07}\right) \lambda_{A N, 1}=\lambda_{A N, 2}=0$. The unexpected surprises from the overnight returns of ADRs have no impact on the daytime returns of their underlying securities.

$\left(\mathrm{H}_{08}\right) \quad \lambda_{S N, 0}=\lambda_{S N, 1}=0$. The unexpected surprises from the overnight returns of ADRs' underlying securities have no impact on the daytime returns of the underlying securities themselves.

$\left(\mathrm{H}_{09}\right) \quad \beta_{A N, 0}=\beta_{A N, 1}=0$. The unanticipated innovations from the overnight returns of ADRs have no influence on the volatility of daytime returns of ADRs themselves.

$\left(\mathrm{H}_{10}\right) \quad \beta_{S N, 0}=\beta_{S N, 1}=0$. The unanticipated innovations from the overnight returns of the underlying securities have no influence on the volatility of daytime returns of their ADRs.

$\left(\mathrm{H}_{11}\right) \omega_{A N, 1}=\omega_{A N, 2}=0$. The unanticipated innovations from the overnight returns of ADRs have no influence on the volatility of daytime returns of their underlying securities.

$\left(\mathrm{H}_{12}\right) \omega_{S N, 0}=\omega_{S N, 1}=0$. The unanticipated innovations from the overnight returns of ADRs' underlying securities have no influence on the volatility of daytime returns of the underlying securities themselves.

$$
\begin{aligned}
\left(\mathrm{H}_{13}\right) \quad \theta_{A N, 0} & =\theta_{A N, 1}=\theta_{S N, 0}=\theta_{S N, 1}=0, \quad \lambda_{A N, 1}=\lambda_{A N, 2}=\lambda_{S N, 0}=\lambda_{S N, 1}=0, \\
\beta_{A N, 0} & =\beta_{A N, 1}=\beta_{S N, 0}=\beta_{S N, 1}=0, \quad \omega_{A N, 1}=\omega_{A N, 2}=\omega_{S N, 0}=\omega_{S N, 1}=0 .
\end{aligned}
$$

There is no influence on the means and volatilities of daytime returns for ADRs and their underlying securities from the unexpected information of their overnight returns.

The results in Table 8 show that the null hypotheses $\mathrm{H}_{05}$ and $\mathrm{H}_{08}$ are rejected for Chinese and Taiwanese firms. It indicates that the unexpected surprises from the overnight returns would affect the daytime returns of the ADRs and the underlying securities, respectively, for Chinese and Taiwanese firms. Besides, the $\mathrm{H}_{06}$ and $\mathrm{H}_{07}$ are both rejected for Taiwanese firms. It reveals that for Taiwanese firms, the daytime returns of the ADRs would be affected by the unexpected surprises from the overnight returns of their underlying securities, and the daytime returns of the underlying securities would also be affected by the unexpected surprises from the overnight returns of their ADRs. However, only the $\mathrm{H}_{06}$ is rejected for Chinese firms. It suggests that for Chinese firms, the daytime returns of the ADRs would be affected by the unexpected surprises from the overnight returns of their underlying securities, but the daytime returns of the underlying securities would not be significantly affected by the unexpected surprises from the overnight returns of their ADRs. Therefore, there are information transmission effects from the overnight returns to the daytime returns for the ADRs and their underlying securities.

As for the test results of volatility spillover effects, Table 8 also shows that the null hypotheses $\mathrm{H}_{09}$ and $\mathrm{H}_{12}$ are rejected for Chinese and Taiwanese firms. It implies that the unanticipated innovations from the overnight returns would affect the volatility of daytime returns of the ADRs and the underlying securities, respectively, for Chinese and Taiwanese firms. Moreover, the $\mathrm{H}_{10}$ and $\mathrm{H}_{11}$ are both rejected for Taiwanese firms. It suggests that for Taiwanese firms, the volatility of daytime returns of the ADRs would be affected by the unanticipated innovations from the overnight returns of their underlying securities, and the volatility of daytime returns of the underlying securities 
would also be affected by the unanticipated shocks from the overnight returns of their ADRs. However, only the $\mathrm{H}_{10}$ is rejected for Chinese firms. It indicates that for Chinese firms, the volatility of daytime returns of the ADRs would be affected by the unanticipated innovations from the overnight returns of their underlying securities, but the volatility of daytime returns of the underlying securities would not be significantly affected by the unanticipated shocks from the overnight returns of their ADRs. Finally, the $\mathrm{H}_{13}$ is also rejected for Chinese and Taiwanese firms. Consequently, there are information transmission and spillover effects from the unanticipated shocks of the overnight returns to the means and volatilities of the daytime returns for ADRs and their underlying securities.

Table 8. Results of the likelihood ratio tests for hypothesis testing

\begin{tabular}{|c|c|c|c|c|}
\hline \multirow[b]{2}{*}{ Hypotheses testing } & \multicolumn{2}{|c|}{ Chinese firms } & \multicolumn{2}{|c|}{ Taiwanese firms } \\
\hline & $\begin{array}{l}\text { Chi-square } \\
\text { statistics }\end{array}$ & P-value & $\begin{array}{l}\text { Chi-square } \\
\text { statistics }\end{array}$ & P-value \\
\hline $\mathrm{H}_{01}: \phi_{A D^{+}, 1}=\phi_{A D^{-}, 1} ; \phi_{A D^{+}, 2}=\phi_{A D^{-}, 2}$ & $9.96522^{* * *}$ & 0.00686 & 2.47197 & 0.29055 \\
\hline $\mathrm{H}_{02}: \phi_{S D^{+}, 1}=\phi_{S D^{-}, 1} ; \phi_{S D^{+}, 2}=\phi_{S D^{-}, 2}$ & 3.34187 & 0.18807 & 2.65002 & 0.26580 \\
\hline $\mathrm{H}_{03}: \psi_{S D^{+}, 1}=\psi_{S D^{-}, 1} ; \psi_{S D^{+}, 2}=\psi_{S D^{-}, 2}$ & $6.79126^{* *}$ & 0.03352 & $4.75138^{*}$ & 0.09295 \\
\hline $\mathrm{H}_{04}: \psi_{A D^{+}, 1}=\psi_{A D^{-, 1}} ; \psi_{A D^{+}, 2}=\psi_{A D^{-,}, 2}$ & 2.03276 & 0.36190 & 3.93110 & 0.14008 \\
\hline $\mathrm{H}_{05}: \theta_{A N, 0}=\theta_{A N, 1}=0$ & $69.04725^{* * *}$ & 0.00000 & $20.21831^{* * *}$ & 0.00004 \\
\hline $\mathrm{H}_{06}: \theta_{S N, 0}=\theta_{S N, 1}=0$ & $10.95207^{* * *}$ & 0.00419 & $11.17790^{* * *}$ & 0.00374 \\
\hline $\mathrm{H}_{07}: \quad \lambda_{A N, 1}=\lambda_{A N, 2}=0$ & 3.72903 & 0.15497 & $14.24052^{* * *}$ & 0.00081 \\
\hline $\mathrm{H}_{08}: \quad \lambda_{S N, 0}=\lambda_{S N, 1}=0$ & $24.13807^{* * *}$ & 0.00001 & $16.10473^{* * *}$ & 0.00032 \\
\hline $\mathrm{H}_{09}: \quad \beta_{A N, 0}=\beta_{A N, 1}=0$ & $9.51537^{* * *}$ & 0.00859 & $10.25449^{* * *}$ & 0.00593 \\
\hline $\mathrm{H}_{10}: \quad \beta_{S N, 0}=\beta_{S N, 1}=0$ & $8.48605^{* *}$ & 0.01436 & $6.93042^{* *}$ & 0.03127 \\
\hline $\mathrm{H}_{11}: \quad \omega_{A N, 1}=\omega_{A N, 2}=0$ & 4.41073 & 0.11021 & $8.05106^{* *}$ & 0.01785 \\
\hline $\mathrm{H}_{12}: \quad \omega_{S N, 0}=\omega_{S N, 1}=0$ & $13.71209^{* * *}$ & 0.00105 & $11.26042^{* * *}$ & 0.00359 \\
\hline $\begin{aligned} & \mathrm{H}_{13}: \begin{array}{l}\theta_{A N, 0} \\
\lambda_{A N, 1}\end{array}=\theta_{A N, 1}=\lambda_{A N, 2}=\lambda_{S N, 0}=\lambda_{S N, 1}=0 \\
& \lambda_{S N, 1}=0 \\
& \beta_{A N, 0}=\beta_{A N, 1}=\beta_{S N, 0}=\beta_{S N, 1}=0 \\
& \omega_{A N, 1}=\omega_{A N, 2}=\omega_{S N, 0}=\omega_{S N, 1}=0\end{aligned}$ & $44.01403^{* * *}$ & 0.00020 & $35.00219^{* * *}$ & 0.00397 \\
\hline
\end{tabular}

Notes:

1. The Likelihood Ratio (LR) test statistics follow the chi-square distribution.

2. *,**, and *** stand for significance at the $10 \%, 5 \%$, and $1 \%$ level, respectively.

\section{Conclusion}

This study employs the two-stage bivariate GJR-GARCH models to analyze the information transmission dynamics of risk and returns for the Chinese and Taiwanese ADRs and their underlying foreign securities. In the first stage, we estimate the unexpected returns that cannot be predicted based on the information from the prior overnight returns of the ADRs and their underlying securities. In the second stage, we further examine the potential asymmetric reactions in the means and volatilities of the daytime returns for the ADRs and their underlying securities, by taking into account the exogenous influence from the additional information of the overnight returns on the ADRs and their underlying securities as well. The two-stage bivariate GJR-GARCH models not only consider the possible interdependence between the overnight returns and the daytime returns of both the ADRs and their underlying securities, but also reflect the information transmission dynamics of returns and volatilities between the ADRs and their underlying foreign securities. 
The empirical results of this study indicate that the mean and volatility spillover effects and information transmission between ADRs and their underlying securities are bi-directional for the Taiwanese securities, but there are different degrees of impacts from different directions. Our results demonstrate that the information transmission from Taiwanese ADRs to their underlying securities is slightly stronger than that from Taiwanese underlying securities to their ADRs. While the international financial center hypothesis and the home bias hypothesis are both supported for the Taiwanese sample, the effect of the international financial center hypothesis appears to be greater for these Taiwanese securities cross-listed in US stock markets. On the other hand, our empirical results reveal that the information transmission from Chinese underlying securities to their ADRs is much stronger than that from Chinese ADRs to their underlying securities. The results are more in favor of the home bias hypothesis for the Chinese ADRs and their underlying securities. Consequently, while ADRs can provide US investors with attractive investment opportunities to form international portfolios and to achieve the international diversification benefits, US investors still need to pay special attention to the important information from the local markets of the ADRs' foreign underlying securities in order to make the appropriate investment decisions.

\section{References}

Alaganar, V. T., \& Bhar, R. (2001). Diversification gains from American depositary receipts and foreign equities: Evidence from Australian stocks, Journal of International Financial Markets, Institutions and Money, 11, 97-113. https://doi.org/10.1016/S1042-4431(00)00038-X

Alaganar, V. T., \& Bhar, R. (2002). Information and volatility linkage under external shocks: Evidence from dually listed Australian stocks, International Review of Financial Analysis, 11, 59-71. https://doi.org/10.1016/S1057-5219(01)00070-9

Bollerslev, T. (1986). Generalized autoregressive conditional heteroskedasticity, Journal of Financial Economics, 31, 307-327. https://doi.org/10.1016/0304-4076(86)90063-1

Booth, G. G., Martikainen, T., \& Tse, Y. (1997). Price and volatility spillovers in Scandinavian stock markets. Journal of Banking and Finance, 21, 811-823. https://doi.org/10.1016/S0378-4266(97)00006-X

Choi, Y. K., \& Kim, D. S. (2000). Determinants of American depositary receipts and their underlying stock returns: Implications for international diversification. International Review of Financial Analysis, 9, 351-368. https://doi.org/10.1016/S1057-5219(00)00041-7

Dodd, O., \& Gilbert, A. (2016). The impact of cross-listing on the home market's information environment and stock price efficiency, Financial Review, 51, 299-328. https://doi.org/10.1111/fire.12110

Ejara, D. D., \& Ghosh, C. (2004). Impact of ADR listing on the trading volume and volatility in the domestic market. Multinational Finance Journal, 8, 247-274. https://doi.org/10.17578/8-3/4-5

Engle, R. F. (1982). Autoregressive conditional heteroscedasticity with estimates of the variance of United Kingdom inflation, Econometrica, 50, 987-1008. https://doi.org/10.2307/1912773

Engle, R. F., \& Granger, C. W. J. (1987). Co-integration and error-correction: Representation, estimation and testing, Econometrica, 55, 252-276. https://doi.org/10.2307/1913236

Engle, R. F., \& Ng, V. K. (1993). Measuring and testing the impact of news on volatility, Journal of Finance, 48, 1749-1778. https://doi.org/10.1111/j.1540-6261.1993.tb05127.x

Eun, C. S., \& Shim, S. (1989). International transmission of stock market movements, Journal of Financial and Quantitative analysis, 24, 241-256. https://doi.org/10.2307/2330774

Fatemi, A. M., \& Park, J. (1996). Seasonal patterns in Japanese ADR returns and the US stock market influence, Journal and the World Economy, 8, 65-79. https://doi.org/10.1016/0922-1425(95)00017-8

Ghadhab, I., \& Hellara, S. (2016). Price discovery of cross-listed firms, International Review of Financial Analysis, 44, 177-188. https://doi.org/10.1016/j.irfa.2016.01.017

Granger, C. W. J., \& Newbold, P. (1974), Spurious regressions in econometrics, Journal of Econometrics, 2, 111-120. https://doi.org/10.1016/0304-4076(74)90034-7

Hamao, Y., Masulis, R. W., \& Ng, V. (1990). Correlations in price changes and volatility across international stock markets, Review of Financial Studies, 3, 281-307. https://doi.org/10.1093/rfs/3.2.281

Howe, J. S., \& Ragan, K. P. (2002). Price discovery and the international flow of information, Journal of International Financial Markets, Institutions and Money, 12, 201-215. 
https://doi.org/10.1016/S1042-4431(02)00003-3

Huang, Y., Jacoby, G., \& Jiang, C. X. (2016). The bonding hypothesis and the home market liquidity of Chinese cross-listed stocks, Journal of International Financial Markets, Institutions \& Money, 43, 146-157. https://doi.org/10.1016/j.intfin.2016.04.003

Huo, R., \& Ahmed, A. D. (2017). Return and volatility spillovers effects: Evaluating the impact of Shanghai-Hong Kong Stock Connect, Economic Modelling, 61, 260-272. https://doi.org/10.1016/j.econmod.2016.09.021

Jeong, J. G. (1999). Cross-border transmission of stock price volatility: Evidence from the overlapping trading hours. Global Finance Journal, 10, 53-70. https://doi.org/10.1016/S1044-0283(99)00005-8

Jiang, C. X. (1998). Diversification with American depository receipts: The dynamics and the pricing factors, Journal of Business Finance and Accounting, 25, 638-699. https://doi.org/10.1111/1468-5957.00207

Johansen, S. (1988). Statistical analysis of cointegration vectors, Journal of Economic Dynamics and Control, 12, 231-254. https://doi.org/10.1016/0165-1889(88)90041-3

Kim, D., \& Kon, S. J. (1994). Alternative models for the conditional heteroscedasticity of stock returns, Journal of Business, 67, 563-598. https://doi.org/10.1086/296647

Kim, M., Szakmary, A. C., \& Mathur, I. (2000). Price transmission dynamics between ADRs and their underlying foreign securities, Journal of Banking \& Finance, 24, 1359-1382. https://doi.org/10.1016/S0378-4266(99)00076-X

Kim, S. J. (2003). The spillover effects of US and Japanese public information news in advanced Asia-Pacific stock markets, Pacific-Basin Finance Journal, 11, 611-630. https://doi.org/10.1016/S0927-538X(03)00015-5

Kot, H. W., \& Tam, L. H. K. (2016). Are stock price more informative after dual-listing in emerging markets? Evidence from Hong Kong-listed Chinese companies, Pacific-Basin Finance Journal, 36, 31-45. https://doi.org/10.1016/j.pacfin.2015.12.004

Koulakiotis, A., Angelidis, D., Tolikas, K., \& Molyneux, P. (2006). The impact of foreign cross-listings on the home Dutch equities. Managerial Finance, 32, 451-462. https://doi.org/10.1108/03074350610657463

Kutan, A. M., \& Zhou, H. (2006). Determinants of returns and volatility of Chinese ADRs at NYSE. Journal of Multinational Financial Management, 16, 1-15. https://doi.org/10.1016/j.mulfin.2005.02.003

Kwiatkowski, D., Phillips, P. C. B., Schmidt, P., \& Shin, Y. (1992). Testing the null hypothesis of stationarity against the alternative of a unit root, Journal of Econometrics, 54, 159-178. https://doi.org/10.1016/0304-4076(92)90104-Y

Lee, B. S., \& Rui, O. M. (2002). The dynamic relationship between stock returns and trading volume: Domestic and cross-country evidence. Journal of Banking and Finance, 26, 51-78. https://doi.org/10.1016/S0378-4266(00)00173-4

Lee, B. S., Rui, O. M., \& Wang, S. S. (2004). Information transmission between the NASDAQ and Asian second board markets. Journal of Banking and Finance, 28, 1637-1670. https://doi.org/10.1016/j.jbankfin.2003.05.001

Martell, T. F., Rodriguez, L. Jr., \& Webb, G. P. (1999). The impact of listing Latin American ADRs on the risks and returns of the underlying shares. Global Finance Journal, 10, 147-160. https://doi.org/10.1016/S1044-0283(99)00013-7

Nelson, C. R., \& Plosser, C. I. (1982). Trends and random walks in macroeconomic time series: Some evidence and implications, Journal of Monetary Economics, 10, 139-162. https://doi.org/10.1016/0304-3932(82)90012-5

$\mathrm{Ng}$, A. (2000). Volatility spillover effects from Japan and the US to the Pacific-Basin. Journal of International Money and Finance, 19, 207-233. https://doi.org/10.1016/S0261-5606(00)00006-1

Niarchos, N., Tse, Y., Wu, C., \& Young, A. (1999). International transmission of information: A study of the relationship between the U.S. and Greek stock markets. Multinational Finance Journal, 3, 19-40. https://doi.org/10.17578/3-1-2

Park, J. (1995). Variance of ADR returns: Information effect and influence of trading in the U.S. market. International Review of Economics and Finance, 4, 105-114. https://doi.org/10.1016/1059-0560(95)90012-8

Patro, D. K. (2000). Return behavior and pricing of American depositary receipts, Journal of International Financial Markets, Institutions and Money, 9, 43-67. https://doi.org/10.1016/S1042-4431(99)00024-4 
Phillips, P. C. B., \& Perron, P. (1988). Testing for a unit root in time series regression, Biometrika, 75, 335-346. https://doi.org/10.1093/biomet/75.2.335

Said, S. E., \& Dickey, D. A. (1984). Testing for unit roots in autoregressive-moving average models of unknown order, Biometrika, 71, 599-607. https://doi.org/10.1093/biomet/71.3.599

Sheng, X., Brzeszczynski, J., \& Ibrahim, B. M. (2017). International stock return co-movements and trading activity, Finance Research Letters, 23, 12-18. https://doi.org/10.1016/j.frl.2017.06.006

Theodossiou, P., \& Lee, U. (1993). Mean and volatility spillovers across major national stock markets: Further empirical evidence. Journal of Financial Research, 16, 337-350. https://doi.org/10.1111/j.1475-6803.1993.tb00152.x

Wang, S. S., Rui, O. M., \& Firth, M. (2002). Return and volatility behavior of dually-traded stocks: The case of Hong Kong. Journal of International Money and Finance, 21, 265-293. https://doi.org/10.1016/S0261-5606(01)00039-0

Wei, K. C. J., Liu, Y. J., Yang, C. C., \& Chaung, G. S. (1995) Volatility and price change spillover effects across the developed and emerging markets. Pacific-Basin Finance Journal, 3, 113-136. https://doi.org/10.1016/0927-538X(94)00029-7 